\title{
Cytokine-based Cancer Immunotherapy: Challenges and Opportunities for IL-10
}

\author{
KATHRINE S. RALLIS ${ }^{1}$, AMBER E. CORRIGAN ${ }^{2}$, HASHIM DADAH ${ }^{2}$, ALAN MATHEW GEORGE ${ }^{3,4}$, \\ SUMIRAT M. KESHWARA ${ }^{4}$, MICHAIL SIDERIS ${ }^{5}$ and BERNADETT SZABADOS ${ }^{6}$
}

\author{
${ }^{1}$ Barts and The London School of Medicine and Dentistry, Queen Mary University of London, London, U.K.; \\ ${ }^{2}$ GKT School of Medicine, King's College London, London, U.K.; \\ ${ }^{3}$ Institute of Inflammation and Ageing, University of Birmingham, Birmingham, U.K.; \\ ${ }^{4}$ Liverpool School of Medicine, University of Liverpool, Liverpool, U.K.; \\ ${ }^{5}$ Women's Health Research Unit, Queen Mary University of London, London, U.K.; \\ ${ }^{6}$ Barts Cancer Institute, Queen Mary University of London, London, U.K.
}

\begin{abstract}
Cancer immunotherapy is an evolving field of research. Cytokines have been conceptualized as an anticancer therapy for longer than most other cancer immunotherapy modalities. Yet, to date, only two cytokines are FDA-approved: $I F N-\alpha$ and IL-2. Despite the initial breakthrough, both agents have been superseded by other, more efficacious agents such as immune checkpoint inhibitors. Several issues persist with cytokine-based cancer therapies; these are broadly categorised into a) high toxicity and b) low efficacy. Despite the only moderate benefits with early cytokine-based cancer therapies, advances in molecular engineering, genomics, and molecular analysis hold promise to optimise and reinstate cytokine-based therapies in future clinical practice. This review considers five important concepts for the successful clinical application of cytokine-based cancer therapies including: (i) improving pharmacokinetics and pharmacodynamics, (ii) improving local administration strategies, (iii) understanding context-dependent interactions in the tumour-microenvironment, (iv) elucidating the role of genetic polymorphisms, and (v) optimising combination therapies. IL-10 has been the focus of attention in recent years and is discussed herein as an example.
\end{abstract}

This article is freely accessible online.

Correspondence to: Kathrine S. Rallis, MSc, Barts and The London School of Medicine and Dentistry, Turner Street, Whitechapel, London E1 2AD, U.K. Tel: +44 7546272233, e-mail: k.s.rallis@smd16.qmul.ac.uk

Key Words: Cytokines, cancer immunotherapy, pharmacokinetics (PK), pharmacodynamics (PD), tumour microenvironment (TME), single nucleotide polymorphisms (SNPs), combination therapy, IL10 , pegilodecakin, review.
Cytokines are soluble, low molecular weight proteins that mediate cell-to-cell communication. They are able to modulate the host immune response toward cancer cells and directly induce their apoptosis. Cytokine-based immunotherapy has been a promising area of research, yet to date, only IFN- $\alpha$ and IL-2 (1) have received FDA approval for cancer therapy. Moreover, these agents have been superseded by safer and more efficacious therapies such as immune checkpoint inhibitors (ICIs) (2).

Several issues persist with cytokine-based immunotherapies. These are broadly categorised into: a) high toxicity and b) low efficacy (2). The vast pleiotropism and redundancy in cytokine signalling, as well as dual immunosuppressive and immunostimulatory functions contribute to suboptimal safety and efficacy (3). Despite moderate benefits with early cytokine therapies, it remains an important field of research, especially considering progresses with IL-10.

This review addresses five obstacles in the clinical translation of next generation cytokine cancer immunotherapies. These include: (i) enhancing pharmacokinetics and pharmacodynamics; (ii) improving local administration; (iii) understanding context-dependent interactions in the tumour microenvironment (TME); (iv) elucidating the role of genetic polymorphisms; and (v) optimising combination therapy. We explore possible avenues in these domains listing biotechnological advances. IL-10 is used as a focused example.

\section{IL-10 in Cancer Therapy: Between Pro-tumorigenic Inflammation and Anti-tumour Immunity - From Old to New}

IL-10 is a pleiotropic cytokine with anti-inflammatory and immunostimulatory functions. In cancer, IL-10 may exert pro- or anti-tumour effects (4). Early research aimed to 
neutralise IL-10 to mediate tumour rejection via T-cell stimulation. However, this approach has been limited by severe life-threating inflammatory toxicities (4).

Current research focuses on increasing local IL-10 concentrations in the TME to mediate tumour regression since IL-10-dependent $\mathrm{CD}^{+}{ }^{+}$T-cell stimulation induces tumour-specific immunity (4). In vivo, IL-10's anti-tumour mechanisms are well-documented $(5,6)$ and work synergistically with anti-PD-1 therapy $(5,7)$. Yet, a phase Ib trial, failed to show added benefit with the combination of IL-10 and pembrolizumab or nivolumab (8). Nevertheless, data could simply imply that IL-10 might not overcome ICI resistance in this setting (9).

Significant are also novel findings regarding the impact of receptor binding. IL-10R is composed of $\alpha$ and $\beta$ subunits. Researchers engineered an IL-10 construct with potent immunomodulatory effects because it targeted IL-10R $\beta$ with higher affinity (10). Thus, the relative affinity and avidity of IL-10 to receptor subunits may offer insight into lack of efficacy in certain settings.

\section{Enhancing Pharmacokinetics and Pharmacodynamics}

Chemical and physical instability limits cytokine therapies. Short half-life (11) and in vivo proteolytic enzymatic degradation necessitate high doses and frequent administration (12). Protein handling and storage, including freeze-thaw cycles and storage time, affect stability, causing denaturation and activity variations $(12,13)$.

IL-10 conjugation with polyethylene glycol (pegylation), creating pegilodecakin, increases serum half-life. In vitro, pegilodecakin inhibits tumour growth by oligoclonal expansion of tumour-specific $\mathrm{CD}^{+}$T-cells $(14,15)$. Clinically, pegilodecakin induces $\mathrm{CD} 8^{+}$immunity, elevating IFN- $\gamma$ and granzyme B with acceptable toxicity $(5,6)$. Combination with anti-PD-1 (nivolumab) is safe and efficacious in phase I setting (8).

Conjugation to polyvinylpyrolidone (PVP)-coated silver nanoparticles also improves pharmacokinetics (12). PVPconjugates are retained in the blood increasing serum halflife (16). Silver (Ag) nanoparticles also mediate antiinflammation $(17,18)$. Preclinically, conjugation of IL-10 to PVP-coated silver nanoparticles increased its antiinflammatory characteristics (12). Furthermore, Ag-PVP conjugated IL-10 retained its effectiveness despite storage condition variations, compared to mouse recombinant IL-10, which showed decreased activity (12).

A further approach to improve pharmacokinetics is extracellular vesicle (EV)-loading. EVs are natural cell products and function as inter-cellular protein transporters (19). A recent study outlines a method of delivering IL-10 using EVs in a murine model of ischaemic acute kidney injury (AKI) (20). EVs could be targeted to the kidney using adhesive EV surface components conferring desired therapeutic properties.

Antibody fusion creating immunocytokines, also known as bispecific antibodies (BsAbs), has also been investigated (21). Cetuximab-based IL-10 fusion protein CmAb-(IL10)2 developed by the conjugation of IL-10 with the epidermal growth factor receptor (EGFR) inhibitor cetuximab, demonstrated pre-clinical antitumor efficacy (8). CmAb(IL10)2, increased half-life and reduced toxicity compared to systemic IL-10. CmAb-(IL-10) inhibits tumour growth, and when combined with anti-PD-1 and anti-CTLA-4, decreases $\mathrm{CD}^{+}{ }^{+} \mathrm{T}$-cell apoptosis. Bispecific antibodies have higher avidity and specificity as they interact with two surface antigens $(22,23)$.

\section{Confining Effects to Tumour Location}

Localising cytokine administration to the tumour may reduce toxicity and enhance efficacy of cytokine immunotherapy reducing systemic off-target proinflammatory effects and increasing local drug concentrations, respectively.

Although a potent anti-inflammatory cytokine, at high doses IL-10 has immunostimulatory effects on $\mathrm{CD} 4^{+}, \mathrm{CD} 8^{+}$, and/or NK cells increasing IFN- $\gamma$ production (24), which induces antitumor activity (25). Injecting IL-10 directly into the tumour achieves sufficiently high drug concentrations to increase other cytokine levels such as IFN- $\gamma$, IL-4 and IL18. IFN- $\gamma$ upregulates MHC-I on tumour and dendritic cells improving $\mathrm{CD}^{+} \mathrm{T}$-cell anti-tumour cytotoxicity (6).

Unlike recombinant IL-10 injection, gene therapy vectors offer tailored gene manipulation, fewer production limitations, and efficient protein production with appropriate post transcription modifications (26). Adenoviral-mediated expression of IL-10 has been used for immunosuppression in autoimmune conditions (27). However, safety limitations restrict adenovirus-based therapy to single administration (26).

Oncolytic viruses armed with IL-10 have been studied in murine pancreatic cancer models (28). Using a tumourtargeted oncolytic vaccinia virus containing IL-10, researchers observed twice as many survivors. Almost $90 \%$ of responding mice showed complete tumour clearance, compared to $40 \%$ treated with the unarmed virus. Increased macrophage infiltrate and MHC-II downregulation in the IL10 condition indicate enhanced tumour rejection through innate and adaptive immunity modulation.

Nano-carriers selectively target cells for tumour eradication (29). Lipid nanoparticles enable substance loading (e.g., drugs and mRNA) for vector transfection. Effective targeted delivery for selective mRNA-based protein expression could decrease offtarget expression and enhance efficacy (26). Lipid nanoparticle mRNA delivery of $\mathrm{IL}-10$ has been applied in vivo for inflammatory conditions (26) and could be expanded to cancers. 


\section{Understanding the Context-dependent Interaction Within the TME}

The TME differs between each cancer: different tissues, different malignant cells-of-origin, and different stroma. Considering the distinct immune cells, contexts of stimulation, and concentrations of multiple factors involved is important (30). Therapeutic alteration of IL-10 in the TME produces paradoxical outcomes $(30,31)$.

The TME encourages chronic inflammation whilst suppressing acute inflammatory responses to maintain tumour growth. Tumours associated with worse prognosis exhibit higher tumour-associated macrophage (TAM) and Tregulatory cell (Treg) concentrations, and fewer tumourinfiltrating lymphocytes. IL-10 propagates pro- and antiinflammatory processes maintaining homeostasis of antiinflammatory Tregs and suppression of proinflammatory IL17-expressing T cells (Th17) (4).

The anticancer effect of IL-10 is hypothesized to occur through: (i) reduction of tumour-promoting inflammation and (ii) stimulation of $\mathrm{CD}^{+} \mathrm{T}$ cells in the tumour milieu (4). IL10 stabilises Tregs which dampen the immune response (32). It also promotes inflammation via pro-inflammatory cytokine induction such as IFN- $\gamma$ and granzyme B which induce MHC-I/II for tumour antigen presentation. IL-10 induces $\mathrm{CD}^{+} \mathrm{T}$-cell cytotoxicity (33) and, in its pegylated form, effectively induces tumour rejection (4).

Pro-tumorigenicity is mediated by diminished anti-tumour immunity (31). IL-10 negatively regulates proinflammatory IL-6 and IL-12/IL-23 signalling and reduces antigen presentation by downregulating MHC-II on APCs (34) and MHC-I on tumour cells (35) promoting tumour immune escape. TAMs secrete IL-10 hence levels correlate with tumour growth $(31,36)$. Tumours themselves release IL-10 contributing to immunosuppression [reviewed in (31)]. Concomitant IL-10R expression on tumours supports an autocrine signalling model (37). Although IL-10 correlates with tumour progression the multiple factors involved have prevented establishment of causality (31).

\section{Elucidating the Role of SNPs}

From the mid-2000s, 22 studies (38), spanning 13 malignancies (39), highlighted associations between IL-10 SNPs and cancer. While these were limited in cohort size and cause-and-effect relationships, they incited investigation. Given IL-10's importance in cancers (40-42), the impact of SNPs on molecular functioning is crucial.

At least 49 IL-10 SNPs have been reported within the likes of Ensemble Genome Browser databases (39). IL-10 variants induce differential protein expression. For example, IL-10-1082, -819, and -592 SNP haplotypes demonstrate differential expression in vitro (43). Genetic variation accounts for up to $75 \%$ of interindividual differences (44). Differences in post-transcriptional regulation have been described: IL-10 mRNA stability varies indicating cellspecific interactions (43).

Contradictory findings have been reported on IL-10's role in carcinogenesis. Studies suggest SNPs are directly implicated in breast cancer. IL-10-593C $>$ A polymorphisms modify disease free and overall survival in lymph-nodepositive cancer after adjusting for clinical parameters including estrogen and progesterone receptor status (45). SNPs such as $-1082 \mathrm{~A} / \mathrm{G}$ predispose to breast cancer, potentially, by conferring an additional transcription factor binding site in the promoter region $(46,47)$. Yet, metaanalyses are conflicting on IL-10 rs1800896 and rs1800871 polymorphisms and breast cancer susceptibility $(38,48,49)$. Equally, studies across prostate $(50-52)$, skin $(53,54)$, lung (55), gastric (56) and cervical cancers $(57,58)$ have not been consistent.

\section{Optimising Combination Therapy}

As aforementioned, IL-10-armed oncolytic viruses doubled the rate of complete responses in pancreatic cancer models (28). Gorby et al. showed that their engineered IL-10 construct improved CAR-T-cell activity in vitro compared to CARs cultured with wild type or no IL-10 (10). Pegilodecakin mediates a sustained increase in serum IL-18 (5), which enhances efficacy and durability of CARexpressing $\mathrm{CD}^{+} \mathrm{T}$ cells $(59,60)$. Combinations with ICIs stem from the understanding that IL-10 mediates antitumour effects through $\mathrm{CD}^{+} \mathrm{T}$ cell stimulation in the tumour milieu while ICIs reinvigorate exhausted $\mathrm{CD}^{+} \mathrm{T}$ cells by supressing inhibitory immune signals (61). Anti-CTLA-4 plus anti-PD-1 tumour regression also depends on IL-7 and IFN- $\gamma$ (62), which are inducible by pegilodecakin (5). In a recent article, Guo et al. provide preclinical evidence that IL10-Fc-based therapy is safe and highly effective in combination with many existing immunotherapies, such as ICIs, cancer vaccines, and adoptive $\mathrm{T}$ cell transfer, potentially complementing and synergizing with these for enhanced efficacy and response rates (63). By promoting oxidative phosphorylation, independently of progenitor exhausted T cells, IL-10-Fc directly and potently enhanced expansion and effector functioning of terminally exhausted $\mathrm{CD}^{+}$tumour-infiltrating lymphocytes, which pose a major challenge in lack of response to ICIs and most other immunotherapies. Established solid tumours were eradicated and durable cures achieved in most treated mice (63). A phase 2 study in advanced melanoma linked increased baseline IL-10 to tumour responses with PD-1 inhibition (64). Moreover, combination of pegilodecakin with pembrolizumab or nivolumab demonstrated a favourable adverse event profile (8). Conversely, the combination of 
pegilodecakin with FOLFOX has failed to improve efficacy as second-line therapy in metastatic pancreatic cancer (65), despite promising early phase data $(66,67)$.

\section{Conclusion}

Cytokines have proven to be an effective anti-cancer therapy, however due to their pleiotropic effect, short half-life and systemic toxicity, they have been surpassed by other targeted agents. New approaches that improve cytokine targeting and alter their pharmacokinetics are being developed. This has resulted in a number of ongoing trials (NCT03193190, NCT04165967), the results of which are eagerly awaited.

\section{Conflicts of Interest}

The Authors declare that they have no competing interests in relation to this study.

\section{Authors' Contributions}

K.S.R.: conceptualization, supervision, reviewing the literature, drafting and revising the article, and final approval of the version to be published. A.E.C., H.D., A.M.G., and S.M.K.: reviewing the literature, drafting and revising the article, and final approval of the version to be published. M.S. and B.S.: supervision, revisions and final approval of the version to be published.

\section{References}

1 Conlon KC, Miljkovic MD and Waldmann TA: Cytokines in the treatment of cancer. J Interferon Cytokine Res 39(1): 6-21, 2019. PMID: 29889594. DOI: 10.1089/jir.2018.0019

2 Berraondo P, Sanmamed MF, Ochoa MC, Etxeberria I, Aznar MA, Pérez-Gracia JL, Rodríguez-Ruiz ME, Ponz-Sarvise M, Castañón E and Melero I: Cytokines in clinical cancer immunotherapy. Br J Cancer 120(1): 6-15, 2019. PMID: 30413827. DOI: 10.1038/s41416-018-0328-y

3 Lee S and Margolin K: Cytokines in cancer immunotherapy. Cancers (Basel) 3(4): 3856-3893, 2011. PMID: 24213115. DOI: 10.3390/cancers3043856

4 Oft M: IL-10: master switch from tumor-promoting inflammation to antitumor immunity. Cancer Immunol Res 2(3): 194-199, 2014. PMID: 24778315. DOI: 10.1158/2326-6066.CIR-13-0214

5 Naing A, Infante JR, Papadopoulos KP, Chan IH, Shen C, Ratti NP, Rojo B, Autio KA, Wong DJ, Patel MR, Ott PA, Falchook GS, Pant S, Hung A, Pekarek KL, Wu V, Adamow M, McCauley S, Mumm JB, Wong P, Van Vlasselaer P, Leveque J, Tannir NM and Oft M: PEGylated IL-10 (Pegilodecakin) induces systemic immune activation, $\mathrm{CD}^{+} \mathrm{T}$ cell invigoration and polyclonal $\mathrm{T}$ cell expansion in cancer patients. Cancer Cell 34(5): 775-791.e3, 2018. PMID: 30423297. DOI: 10.1016/j.ccell.2018.10.007

6 Naing A, Papadopoulos KP, Autio KA, Ott PA, Patel MR, Wong DJ, Falchook GS, Pant S, Whiteside M, Rasco DR, Mumm JB, Chan IH, Bendell JC, Bauer TM, Colen RR, Hong DS, Van Vlasselaer P, Tannir NM, Oft M and Infante JR: Safety, antitumor activity, and immune activation of pegylated recombinant human interleukin-10 (AM0010) in patients with advanced solid tumors. J Clin Oncol 34(29): 3562-3569, 2016. PMID: 27528724. DOI: 10.1200/JCO.2016.68.1106

7 Garon E, Wong D, Schneider J, Aljumaily R, Korn W, Patel M, Autio K, Papadopoulos K, Naing A, Gabrail N, Munster P, Goldman J, Hung A, Oft M, Leveque J and Spigel D: Responses and durability of clinical benefit in non-small cell lung cancer treated with pegilodecakin in combination with anti-PD-1 inhibitors. Annals of Oncology 29: viii407, 2020. DOI: 10.1093/annonc/mdy288.017

8 Naing A, Wong DJ, Infante JR, Korn WM, Aljumaily R, Papadopoulos KP, Autio KA, Pant S, Bauer TM, Drakaki A, Daver NG, Hung A, Ratti N, McCauley S, Van Vlasselaer P, Verma R, Ferry D, Oft M, Diab A, Garon EB and Tannir NM: Pegilodecakin combined with pembrolizumab or nivolumab for patients with advanced solid tumours (IVY): a multicentre, multicohort, openlabel, phase 1b trial. Lancet Oncol 20(11): 1544-1555, 2019. PMID: 31563517. DOI: 10.1016/S1470-2045(19)30514-5

9 Pal S, Hu-Lieskovan S and Agarwal N: Can pegylated IL-10 add to a backbone of PD-1 inhibition for solid tumours? Lancet Oncol 20(11): 1473-1474, 2019. PMID: 31563518. DOI: 10.1016/S1470-2045(19)30619-9

10 Gorby C, Sotolongo Bellón J, Wilmes S, Warda W, Pohler E, Fyfe PK, Cozzani A, Ferrand C, Walter MR, Mitra S, Piehler J and Moraga I: Engineered IL-10 variants elicit potent immunomodulatory effects at low ligand doses. Sci Signal 13(649): eabc0653, 2020. PMID: 32934073. DOI: 10.1126/ scisignal.abc0653

11 Lipiäinen T, Peltoniemi M, Sarkhel S, Yrjönen T, Vuorela H, Urtti A and Juppo A: Formulation and stability of cytokine therapeutics. J Pharm Sci 104(2): 307-326, 2015. PMID: 25492409. DOI: $10.1002 / j p s .24243$

12 Baganizi DR, Nyairo E, Duncan SA, Singh SR and Dennis VA: Interleukin-10 conjugation to carboxylated PVP-coated silver nanoparticles for improved stability and therapeutic efficacy. Nanomaterials (Basel) 7(7): 165, 2017. PMID: 28671603. DOI: 10.3390/nano7070165

13 Cuhadar S, Koseoglu M, Atay A and Dirican A: The effect of storage time and freeze-thaw cycles on the stability of serum samples. Biochem Med (Zagreb) 23(1): 70-77, 2013. PMID: 23457767. DOI: 10.11613/bm.2013.009

14 Mumm JB and Oft M: Pegylated IL-10 induces cancer immunity: the surprising role of IL-10 as a potent inducer of IFN- $\gamma$-mediated CD8(+) T cell cytotoxicity. Bioessays 35(7): 623-631, 2013. PMID: 23666891. DOI: 10.1002/bies.201300004

15 Teng MW, Darcy PK and Smyth MJ: Stable IL-10: a new therapeutic that promotes tumor immunity. Cancer Cell 20(6): 691-693, 2011. PMID: 22172716. DOI: 10.1016/j.ccr.2011.11.020

16 Kaneda Y, Tsutsumi Y, Yoshioka Y, Kamada H, Yamamoto Y, Kodaira H, Tsunoda S, Okamoto T, Mukai Y, Shibata H, Nakagawa $\mathrm{S}$ and Mayumi T: The use of PVP as a polymeric carrier to improve the plasma half-life of drugs. Biomaterials 25(16): 3259-3266, 2004. PMID: 14980420. DOI: 10.1016/j.biomaterials.2003.10.003

17 Yilma AN, Singh SR, Dixit S and Dennis VA: Antiinflammatory effects of silver-polyvinyl pyrrolidone (Ag-PVP) nanoparticles in mouse macrophages infected with live Chlamydia trachomatis. Int J Nanomedicine 8: 2421-2432, 2013. PMID: 23882139. DOI: 10.2147/IJN.S44090 
18 Wong KK, Cheung SO, Huang L, Niu J, Tao C, Ho CM, Che $\mathrm{CM}$ and Tam PK: Further evidence of the anti-inflammatory effects of silver nanoparticles. ChemMedChem 4(7): 1129-1135, 2009. PMID: 19405063. DOI: 10.1002/cmdc.200900049

19 Zhang W, Zhou X, Zhang H, Yao Q, Liu Y and Dong Z: Extracellular vesicles in diagnosis and therapy of kidney diseases. Am J Physiol Renal Physiol 311(5): F844-F851, 2016. PMID: 27582107. DOI: 10.1152/ajprenal.00429.2016

20 Tang TT, Wang B, Wu M, Li ZL, Feng Y, Cao JY, Yin D, Liu H, Tang RN, Crowley SD, Lv LL and Liu BC: Extracellular vesicle-encapsulated IL-10 as novel nanotherapeutics against ischemic AKI. Sci Adv 6(33): eaaz0748, 2020. PMID: 32851154. DOI: $10.1126 /$ sciadv.aaz0748

21 Qiao J, Liu Z, Dong C, Luan Y, Zhang A, Moore C, Fu K, Peng J, Wang Y, Ren Z, Han C, Xu T and Fu YX: Targeting tumors with IL-10 prevents dendritic cell-mediated $\mathrm{CD}^{+} \mathrm{T}$ cell apoptosis. Cancer Cell 35(6): 901-915.e4, 2019. PMID: 31185213. DOI: $10.1016 /$ j.ccell.2019.05.005

22 Sedykh SE, Prinz VV, Buneva VN and Nevinsky GA: Bispecific antibodies: design, therapy, perspectives. Drug Des Devel Ther 12: 195-208, 2018. PMID: 29403265. DOI: 10.2147/DDDT.S151282

23 Schmid AS and Neri D: Advances in antibody engineering for rheumatic diseases. Nat Rev Rheumatol 15(4): 197-207, 2019 PMID: 30814691. DOI: 10.1038/s41584-019-0188-8

24 Lauw FN, Pajkrt D, Hack CE, Kurimoto M, van Deventer SJ and van der Poll T: Proinflammatory effects of IL-10 during human endotoxemia. J Immunol 165(5): 2783-2789, 2000. PMID: 10946310. DOI: 10.4049/jimmunol.165.5.2783

25 Berman RM, Suzuki T, Tahara H, Robbins PD, Narula SK and Lotze MT: Systemic administration of cellular IL-10 induces an effective, specific, and long-lived immune response against established tumors in mice. J Immunol 157(1): 231-238, 1996. PMID: 8683120.

26 Veiga N, Goldsmith M, Granot Y, Rosenblum D, Dammes N, Kedmi R, Ramishetti S and Peer D: Cell specific delivery of modified mRNA expressing therapeutic proteins to leukocytes. Nat Commun 9(1): 4493, 2018. PMID: 30374059. DOI: 10.1038/s41467-018-06936-1

27 Lindsay J: Local delivery of adenoviral vectors encoding murine interleukin 10 induces colonic interleukin 10 production and is therapeutic for murine colitis. Gut 52(3): 363-369, 2020. DOI: 10.1136/gut.52.3.363

28 Chard LS, Lemoine NR and Wang Y: New role of Interleukin-10 in enhancing the antitumor efficacy of oncolytic vaccinia virus for treatment of pancreatic cancer. Oncoimmunology 4(9): e1038689, 2015. PMID: 26405610. DOI: 10.1080/2162402X.2015.1038689

29 Peer D, Karp JM, Hong S, Farokhzad OC, Margalit R and Langer R: Nanocarriers as an emerging platform for cancer therapy. Nat Nanotechnol 2(12): 751-760, 2007. PMID: 18654426. DOI: $10.1038 /$ nnano.2007.387

30 Berti FCB and de Oliveira KB: IL-10 in cancer: Just a classical immunosuppressive factor or also an immunostimulating one? AIMS Allergy Immunol 2: 88-97, 2018. DOI: 10.3934/ Allergy.2018.2.88

31 Mannino MH, Zhu Z, Xiao H, Bai Q, Wakefield MR and Fang Y: The paradoxical role of IL-10 in immunity and cancer. Cancer Lett 367(2): 103-107, 2015. PMID: 26188281. DOI: 10.1016/ j.canlet.2015.07.009

32 Chaudhry A and Rudensky AY: Control of inflammation by integration of environmental cues by regulatory $\mathrm{T}$ cells. J Clin
Invest 123(3): 939-944, 2013. PMID: 23454755. DOI: 10.1172/JCI57175

33 Chen WF and Zlotnik A: IL-10: a novel cytotoxic T cell differentiation factor. J Immunol 147(2): 528-534, 1991. PMID: 1906502.

34 Steinbrink K, Jonuleit H, Müller G, Schuler G, Knop J and Enk $\mathrm{AH}$ : Interleukin-10-treated human dendritic cells induce a melanoma-antigen-specific anergy in CD8(+) T cells resulting in a failure to lyse tumor cells. Blood 93(5): 1634-1642, 1999. PMID: 10029592.

35 Adris S, Klein S, Jasnis M, Chuluyan E, Ledda M, Bravo A, Carbone C, Chernajovsky Y and Podhajcer O: IL-10 expression by CT26 colon carcinoma cells inhibits their malignant phenotype and induces a $\mathrm{T}$ cell-mediated tumor rejection in the context of a systemic Th2 response. Gene Ther 6(10): 17051712, 1999. PMID: 10516719. DOI: 10.1038/sj.gt.3301012

36 Wang T, Ge Y, Xiao M, Lopez-Coral A, Azuma R, Somasundaram R, Zhang G, Wei Z, Xu X, Rauscher FJ 3rd, Herlyn $M$ and Kaufman RE: Melanoma-derived conditioned media efficiently induce the differentiation of monocytes to macrophages that display a highly invasive gene signature. Pigment Cell Melanoma Res 25(4): 493-505, 2012. PMID: 22498258. DOI: 10.1111/j.1755-148X.2012.01005.x

37 Yue FY, Dummer R, Geertsen R, Hofbauer G, Laine E, Manolio S and Burg G: Interleukin-10 is a growth factor for human melanoma cells and down-regulates HLA class-I, HLA class-II and ICAM-1 molecules. Int J Cancer 71(4): 630-637, 1997. PMID: 9178819. DOI: 10.1002/(sici) 1097-0215(19970516)71:4<630::aid-ijc20>3.0. co;2-e

38 Teresa gonzalez-garza M, Elva cruz-vega D and Maldonadobernal C: IL10 as cancer biomarker. Translational Research in Cancer, 2021. DOI: 10.5772/intechopen.90806

39 Howell WM and Rose-Zerilli MJ: Interleukin-10 polymorphisms, cancer susceptibility and prognosis. Fam Cancer 5(2): 143-149, 2006. PMID: 16736283. DOI: 10.1007/s10689-005-0072-3

40 Dummer W, Becker JC, Schwaaf A, Leverkus M, Moll T and Bröcker EB: Elevated serum levels of interleukin-10 in patients with metastatic malignant melanoma. Melanoma Res 5(1): 6768, 1995. PMID: 7734958. DOI: 10.1097/00008390-19950200000008

41 Vera-Lozada G, Minnicelli C, Segges P, Stefanoff G, Kristcevic F, Ezpeleta J, Tapia E, Niedobitek G, Barros MHM and Hassan $\mathrm{R}$ : Interleukin 10 (IL10) proximal promoter polymorphisms beyond clinical response in classical Hodgkin lymphoma: Exploring the basis for the genetic control of the tumor microenvironment. Oncoimmunology 7(5): e1389821, 2018. PMID: 29721365. DOI: 10.1080/2162402X.2017.1389821

42 Donnelly RP, Dickensheets H and Finbloom DS: The interleukin10 signal transduction pathway and regulation of gene expression in mononuclear phagocytes. J Interferon Cytokine Res 19(6): 563573, 1999. PMID: 10433356. DOI: 10.1089/107999099313695

43 Teixeira-Coelho M, Guedes J, Ferreirinha P, Howes A, Pedrosa J, Rodrigues F, Lai WS, Blackshear PJ, O'Garra A, Castro AG and Saraiva M: Differential post-transcriptional regulation of IL-10 by TLR2 and TLR4-activated macrophages. Eur J Immunol 44(3): 856-866, 2014. PMID: 24227629. DOI: 10.1002/eji.201343734

44 Eskdale J, Gallagher G, Verweij CL, Keijsers V, Westendorp RG and Huizinga TW: Interleukin 10 secretion in relation to human IL-10 locus haplotypes. Proc Natl Acad Sci U S A 95(16): 94659470, 1998. PMID: 9689103. DOI: 10.1073/pnas.95.16.9465 
45 Knechtel G, Hofmann G, Gerger A, Renner W, Langsenlehner T, Szkandera J, Wolf G, Samonigg H, Krippl P and Langsenlehner U: Analysis of common germline polymorphisms as prognostic factors in patients with lymph node-positive breast cancer. J Cancer Res Clin Oncol 136(12): 1813-1819, 2010. PMID: 20204402. DOI: 10.1007/s00432-010-0839-2

46 Vinod C, Jyothy A, Vijay Kumar M, Raman RR, Nallari P and Venkateshwari A: A common SNP of IL-10 (-1082A/G) is associated with increased risk of premenopausal breast cancer in South Indian women. Iran J Cancer Prev 8(4): e3434, 2015. PMID: 26478792. DOI: 10.17795/ijcp-3434

47 Howell MW: Interleukin-10 gene polymorphisms and cancer. Landes Bioscience, 2013.

48 Moghimi M, Ahrar H, Karimi-Zarchi M, Aghili K, Salari M, Zare-Shehneh M and Neamatzadeh H: Association of IL-10 rs1800871 and rs 1800872 polymorphisms with breast cancer risk: A systematic review and meta-analysis. Asian Pac J Cancer Prev 19(12): 3353-3359, 2018. PMID: 30583340. DOI: 10.31557/APJCP.2018.19.12.3353

49 Dai ZJ, Wang XJ, Zhao Y, Ma XB, Kang HF, Min WL, Lin S, Yang PT and Liu XX: Effects of interleukin-10 polymorphisms (rs1800896, rs1800871, and rs1800872) on breast cancer risk: evidence from an updated meta-analysis. Genet Test Mol Biomarkers 18(6): 439-445, 2014. PMID: 24720854. DOI: $10.1089 /$ gtmb.2014.0012

50 Shao N, Xu B, Mi YY and Hua LX: IL-10 polymorphisms and prostate cancer risk: a meta-analysis. Prostate Cancer Prostatic Dis 14(2): 129-135, 2011. PMID: 21339768. DOI: $10.1038 /$ pcan 2011.6

51 Liu J, Song B, Bai X, Liu W, Li Z, Wang J, Zheng Y and Wang $\mathrm{Z}$ : Association of genetic polymorphisms in the interleukin-10 promoter with risk of prostate cancer in Chinese. BMC Cancer 10: 456, 2010. PMID: 20735825. DOI: 10.1186/1471-2407-10456

52 Chen H, Tang J, Shen N and Ren K: Interleukin 10 gene rs1800896 polymorphism is associated with the risk of prostate cancer. Oncotarget 8(39): 66204-66214, 2017. PMID: 29029504. DOI: $10.18632 /$ oncotarget.19857

53 Zhao S, Wu D, Wu P, Wang Z and Huang J: Serum IL-10 predicts worse outcome in cancer patients: a meta-analysis. PLoS One 10(10): e0139598, 2015. PMID: 26440936. DOI: 10.1371/journal.pone. 0139598

$54 \mathrm{Wu}$ N, Sun H, Sun Q, Cui M, Jiang R and Cong X: Associations between IL-10 polymorphisms and susceptibility to melanoma, basal cell carcinoma, and squamous cell carcinoma: a metaanalysis. Genet Test Mol Biomarkers, 2018. PMID: 30427744. DOI: $10.1089 /$ gtmb.2018.0172

55 Jafari-Nedooshan J, Moghimi M, Zare M, Heiranizadeh N, Morovati-Sharifabad M, Akbarian-Bafghi MJ, Jarahzadeh MH and Neamatzadeh $\mathrm{H}$ : Association of promoter region polymorphisms of IL-10 gene with susceptibility to lung cancer: Systematic review and meta-analysis. Asian Pac J Cancer Prev 20(7): 1951-1957, 2019. PMID: 31350950. DOI: 10.31557/APJCP.2019.20.7.1951

56 Martínez-Campos C, Torres-Poveda K, Camorlinga-Ponce M, Flores-Luna L, Maldonado-Bernal C, Madrid-Marina V and Torres J: Polymorphisms in IL-10 and TGF- $\beta$ gene promoter are associated with lower risk to gastric cancer in a Mexican population. BMC Cancer 19(1): 453, 2019. PMID: 31092242. DOI: $10.1186 / \mathrm{s} 12885-019-5627-\mathrm{z}$
57 Wang Y, Liu XH, Li YH and Li O: The paradox of IL-10mediated modulation in cervical cancer. Biomed Rep 1(3): 347351, 2013. PMID: 24648946. DOI: 10.3892/br.2013.69

58 Zhang S, Kong YL, Li YL and Yin YW: Interleukin-10 gene -1082 G/A polymorphism in cervical cancer and cervical intraepithelial neoplasia: meta-analysis. J Int Med Res 42(6): 1193-1201, 2014. PMID: 25281063. DOI: 10.1177/0300060514544388

$59 \mathrm{Hu}$ B, Ren J, Luo Y, Keith B, Young RM, Scholler J, Zhao Y and June $\mathrm{CH}$ : Augmentation of antitumor immunity by human and mouse CAR T cells secreting IL-18. Cell Rep 20(13): 3025-3033, 2017. PMID: 28954221. DOI: 10.1016/j.celrep.2017.09.002

60 Chmielewski $\mathrm{M}$ and Abken H: CAR T cells releasing IL-18 convert to T-Bet ${ }^{\text {thigh }}$ FoxO1 low effectors that exhibit augmented activity against advanced solid tumors. Cell Rep 21(11): 32053219, 2017. PMID: 29241547. DOI: 10.1016/j.celrep.2017.11.063

61 Zou W, Wolchok JD and Chen L: PD-L1 (B7-H1) and PD-1 pathway blockade for cancer therapy: Mechanisms, response biomarkers, and combinations. Sci Transl Med 8(328): 328rv4, 2016. PMID: 26936508. DOI: 10.1126/scitranslmed.aad7118

62 Shi LZ, Fu T, Guan B, Chen J, Blando JM, Allison JP, Xiong L, Subudhi SK, Gao J and Sharma P: Interdependent IL-7 and IFN$\gamma$ signalling in T-cell controls tumour eradication by combined $\alpha$-CTLA-4+ $\alpha$-PD-1 therapy. Nat Commun 7: 12335, 2016. PMID: 27498556. DOI: 10.1038/ncomms12335

63 Guo Y, Xie Y, Gao M, Zhao Y, Franco F, Wenes M, Siddiqui I, Bevilacqua A, Wang H, Yang H, Feng B, Xie X, Sabatel C, Tschumi B, Chaiboonchoe A, Wang Y, Li W, Xiao W, Held W, Romero P, Ho P and Tang L: Metabolic reprogramming of terminally exhausted CD8 ${ }^{+} \mathrm{T}$ cells by IL-10 enhances anti-tumor immunity. Nature Immunology 22(6): 746-756, 2021. DOI: 10.1038/s41590-021-00940-2

64 Yamazaki N, Kiyohara Y, Uhara H, Iizuka H, Uehara J, Otsuka F, Fujisawa Y, Takenouchi T, Isei T, Iwatsuki K, Uchi H, Ihn H, Minami $\mathrm{H}$ and Tahara $\mathrm{H}$ : Cytokine biomarkers to predict antitumor responses to nivolumab suggested in a phase 2 study for advanced melanoma. Cancer Sci 108(5): 1022-1031, 2017. PMID: 28266140. DOI: 10.1111/cas.13226

65 Hecht JR, Lonardi S, Bendell J, Sim HW, Macarulla T, Lopez CD, Van Cutsem E, Muñoz Martin AJ, Park JO, Greil R, Wang H, Hozak RR, Gueorguieva I, Lin Y, Rao S and Ryoo BY: Randomized phase III study of FOLFOX alone or with pegilodecakin as second-line therapy in patients with metastatic pancreatic cancer that progressed after gemcitabine (SEQUOIA). J Clin Oncol 39(10): 1108-1118, 2021. PMID: 33555926. DOI: 10.1200/JCO.20.02232

66 Hecht J, Naing A, Falchook G, Patel M, Infante J, Aljumaily R, Wong D, Autio K, Wainberg Z, Javle M, Bendell J, Pant S, Hung A, Van vlasselaer P, Oft $\mathrm{M}$ and Papadopoulos K: Overall survival of PEGylated human IL-10 (AM0010) with 5-FU/LV and oxaliplatin (FOLFOX) in metastatic pancreatic adenocarcinoma (PDAC). Journal of Clinical Oncology 36(4_suppl): 374-374, 2020. DOI: 10.1200/JCO.2018.36.4_suppl.374

67 Autio K and Oft M: Pegylated Interleukin-10: Clinical development of an immunoregulatory cytokine for use in cancer therapeutics. Curr Oncol Rep 21(2): 19, 2019. PMID: 30790069. DOI: $10.1007 / \mathrm{s} 11912-019-0760-\mathrm{z}$

Received June 1, 2021

Revised June 14, 2021

Accepted June 15, 2021 